\title{
Optimal structure of a water cooled pin fin heat sink by Taguchi method depending on various requirements
}

\author{
Hitoshi MATSUSHIMA* and Abdulrahman ALMERBATI** \\ * Department of Mechanical Engineering, Nihon University \\ 1-2-1 Izumi, Narashino-shi, Chiba 275-8575, Japan \\ E-mail: matsushima.hitoshi@nihon-u.ac.jp \\ ** Department of Mechanical Engineering, King Fahd University of Petroleum and Minerals \\ Dhahran 31261, Saudi Arabia
}

Received: 28 May 2021; Revised: 15 July 2021; Accepted: 2 September 2021

\begin{abstract}
Prediction and optimization of water-cooling performance of a pin fin heat sink with variable pin diameters along a flow direction is attempted. We have developed a simple analyze procedure for pin fin heat sink that enables to evaluate the row-by-row performance when diameters of fins are morphed along a flow direction. Validity of the procedure is confirmed for uniform and non-uniform pin diameter cases. The Taguchi method is applied to an optimization method. Optimal design among the considered cases, in which the thermal resistance is minimum, corresponds to the configuration where the pin diameter equals $3 \mathrm{~mm}$ constructed from copper. This holds for constant inlet velocity and constant pumping power cases. Optimum structure of heat sink considering simultaneous parameters (minimum thermal resistance, pressure drop and mass) occurs when the heat sink is built from aluminum with a pin diameter of $2 \mathrm{~mm}$. These three parameters influence the design of the heat sink. For instance, when the thermal resistance and the pressure drop are significant, optimum structure is a "wing like shape" with larger pin diameter near the central rows and copper as material. However, when the thermal resistance and the heat sink mass are of interest, the optimum structure associated with the larger pin diameter constructed from aluminum. Also, when we consider the pressure drop and heat sink mass, the optimum design is the one where the pin diameter is $1 \mathrm{~mm}$ built from aluminum.
\end{abstract}

Keywords : Pin fin, Heat sink, Forced convection, Water cooling, Prediction, Taguchi method, Optimization

\section{Introduction}

Improvement of performance of power modules such as for automobile is very notable in recent years due to the paradigm shift from engine power to electric power. Heat generation density of power modules also increases dramatically. However, reliability of electronics devices like power modules considerably decreases at high temperature, e.g., the fraction defective of such a device increases by $10 \%$ with temperature increase of $20 \mathrm{~K}$ (The Japan Society of Mechanical Engineers ed., 2005). Therefore, improving cooling systems of such electronic devices is highly desired.

Heat sinks are often used to improve a cooling performance of electronic devices. For example, pin fin heat sink is common for water-cooling of automobile power module. Studies of pin fin heat sink so far are mostly focused on pins with uniform diameter. Bejan suggests that design of object with freedom will improve the performance of object itself inevitably (Bejan, 2016). The freedom in design the heat sink leads to better thermal performance (Matsushima, et al., 2018, 2019). There are some studies from this aspect. Bello-Ochende, Meyer and Bejan studied the $2 \times 2$ pin fins with the variation of pin height as well as pin diameter and showed the possibility of thermal performance enhancement (Bello-Ochende et al., 2010). Ramphueiphad and Bureerat conducted an optimization study on pin fins by morphing pin height and shape of cross section with maximum $7 \times 7$ pin fins (Ramphueiphad and Bureerat, 2018).

Considering a productivity of pin fin heat sink, it may be easier and much common to change the pin diameter along the flow direction under the conditions of uniform pin height and same cross-sectional shape. In this study, the 
effect of morphing the pin diameter on the thermal and flow performances of the heat sink is considered. For this purpose, we utilized a simple approach which allows to assess the row-by-row cooling performance of the heat sink when the pin diameter varies along the flow direction. Then, we seek an optimum distribution of pin fin diameter along a flow direction by using the Taguchi method.

\section{Analyze procedure for rows of non-uniform pin diameters}

Fig. 1 shows schematics of an analytical model considered in this study. This is a conceptional simplified model of water-cooled pin fin heat sink for cooling of electronic devices. The heat sink has $28 \mathrm{~mm}$ in width, $28 \mathrm{~mm}$ in length and $12 \mathrm{~mm}$ in fin height. The $7 \times 7$ array of pin fins with fin pitches $x_{L}=4 \mathrm{~mm}, x_{T}=4 \mathrm{~mm}$ is mounted on the heat sink base which has $2 \mathrm{~mm}$ in thickness. Pin diameters considered in this study are $1 \mathrm{~mm}, 2 \mathrm{~mm}$ and $3 \mathrm{~mm}$, respectively. And, there is a gap $G_{p}=1 \mathrm{~mm}$ between fin top and cover (upper wall). Cooling water flows perpendicular to the pin fins, and we set the inlet velocity of $0.2 \mathrm{~m} / \mathrm{s}$ as normal.

- For the sake of simplicity, we have made following assumptions.

Temperature of fin base is fixed and uniform.

Flow in pin fins is similar to that in tube bank.

(We will mainly consider the in-line arrangement in this paper.)

All fluid properties are evaluated at inlet temperature.

- In this study, we considered three objective functions for optimization (Defined in chapter 3).

Total thermal resistance of heat sink; $R_{T}$ (Defined by Eq. (1))

Pressure drop in heat sink; $\Delta P$

Heat sink mass; $M$

Then, we seek the heat sink structure for minimizing the above objective functions under constant inlet velocity or constant pumping power cases.

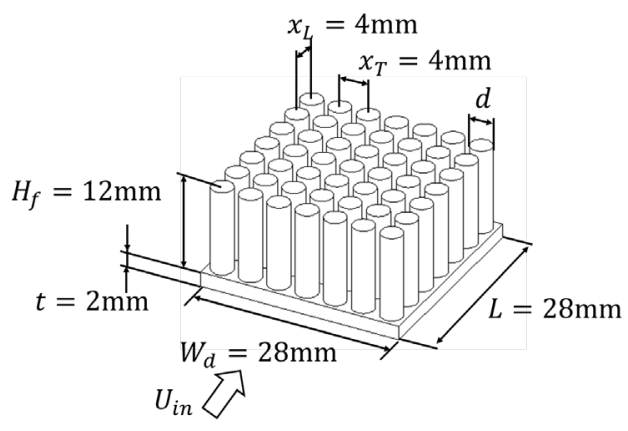

(a) Bird view

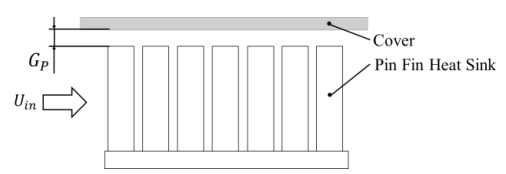

(b) Side view

Fig. 1 Analytical model.

\subsection{Simple analyze procedure for thermal resistance}

Total thermal resistance of heat sink $R_{T}$ is given by,

$$
R_{T}=\frac{1}{\sum\left(A_{i} \cdot \eta_{p i} \cdot h_{i}^{\prime}\right)}
$$

where, $i$ is a number of the row, $A_{i}$ is a heat transfer area of fins at row $i$ include fin base, $\eta_{p i}$ is a fin efficiency of pin fins at row $i$ (Bejan, 1993), and $h_{i}{ }^{\prime}$ is an round-averaged heat transfer coefficient of pin fins at row $i$ considering the effect of water temperature increase around fins. Further, $h_{i}{ }^{\prime}$ is used when evaluating fin efficiency at row $i$.

In this study, heat transfer coefficient of pins at each row is defined by temperature difference between inlet water and pins. This means heat transfer coefficient in downstream rows is apparently decrease from that of upstream rows due to increase of local fluid temperature. Therefore, we developed the equation for this case by applying the $\varepsilon-N T U$ method assuming the pin fin rows as an aggregate of small heat exchangers. Results of this assumption gives following expressions. 


$$
\begin{aligned}
& h_{i}^{\prime}=\frac{h_{i}}{\xi_{i}} \cdot\left(1-e^{-\xi_{i}}\right) \quad \text { for } i=1 \\
& h_{i}^{\prime}=\frac{h_{i}}{\xi_{i}} \cdot\left(1-e^{-\xi_{i}}\right) \cdot \exp \left(-\sum_{k=1}^{i-1} \xi_{k}\right) \quad \text { for } i \geq 2
\end{aligned}
$$

Where, $i$ is a number of each row, $h_{i}$ is the round-averaged heat transfer coefficient of pin fins at row $i$ when the effect of local temperature increase around the fins is not considered. And, $\xi_{k}$ is the term representing the effect of upstream temperature increase of cooling water on heat transfer rate (kind of NTU).

$$
\begin{aligned}
& \xi_{i}=\frac{A_{i} \cdot h_{i}}{\frac{\rho \cdot C_{p} \cdot Q^{\prime}}{\kappa}} \\
& A_{i} \cdot h_{i}=A_{t i} \cdot h_{t i}+A_{p i} \cdot h_{p i}+A_{b i} \cdot h_{b i} \\
& Q=U_{i n} \cdot\left(H_{f}+G_{P}\right) \cdot W_{d} \\
& Q^{\prime}=Q \cdot H_{f} /\left(H_{f}+G_{P}\right)
\end{aligned}
$$

Where, $A_{i} \cdot h_{i}$ is thermal conductance of pin fin heat sink at row $i$ including the fin top, fin side and fin base. $C_{p}$ is heat capacity of water. $Q$ and $Q$ ' are total and partial (within heat sink) volume flow rate of cooling water, respectively. And $\kappa$ is non-uniformity of local fluid temperature from bulk mean temperature (Ashiwake et al., 1983), and we set $\kappa=2.8$ in this study.

We use the correlations of aligned tube bank (Žukauskas, 1972; Bejan, 1993) for estimating heat transfer around pin fins. Furthermore, to treat the variable pin diameters in row by row, we assume that the local heat transfer coefficient at row $i$ is calculated by using maximum average velocity $U_{\text {maxi }}$ there.

$$
\begin{array}{ll}
h_{p i}=\frac{\lambda}{d_{i}} \cdot C_{n} \cdot 0.9 \cdot R e_{i}^{0.4} \cdot P_{r}^{0.36} & \cdots R e_{i} \leq 1 \times 10^{2} \\
h_{p i}=\frac{\lambda}{d_{i}} \cdot C_{n} \cdot 0.52 \cdot R e_{i}^{0.5} \cdot P_{r}^{0.36} & \cdots 1 \times 10^{2}<R e_{i} \leq 1 \times 10^{3} \\
h_{p i}=\frac{\lambda}{d_{i}} \cdot C_{n} \cdot 0.27 \cdot R e_{i}^{0.63} \cdot P_{r}^{0.36} & \cdots 1 \times 10^{3}<R e_{i} \leq 10000
\end{array}
$$

Where,

$$
\begin{aligned}
& R e_{i}=\frac{U_{\text {maxi }} \cdot d_{i}}{v} \\
& C_{n}=0.70(i=1), 0.80(i=2), 0.86(i=3), 0.90(i=4), 0.93(i=5), 0.935(\mathrm{i}=6), 0.95(\mathrm{i}=7) \\
& U_{\text {maxi }}=\frac{Q}{\left(H_{f}+G\right) \cdot W_{d}-N_{i} \cdot H_{f} \cdot d_{i}}
\end{aligned}
$$

Further, we use the following experimental equation for fin base area of pin fin heat sink (Horiuchi et al., 2015).

$$
h_{b i}=\frac{\lambda}{d_{i}} \cdot 0.43 \cdot R e_{i}^{0.51} \cdot P_{r}^{0.36} \cdot\left(\frac{x_{T}}{x_{L}}\right)^{0.2} \quad \ldots\left(\frac{x_{T}}{x_{L}}\right)<2
$$

The flow over the fin top is bypass flow. We assume the flow there is not affected by that in pin fins, and new boundary layer is generated at the leading edge of each fin top. Therefore, we use the correlation for laminar flow along a flat plate with uniform temperature (Bejan, 1993) for fin top area of heat sink.

$$
h_{t i}=\frac{\lambda}{d_{i}} \cdot 0.664 \cdot R e_{i}^{0.5} \cdot P_{r}^{\frac{1}{3}}
$$

In the present model, ratio of fin top area to whole heat sink area is relatively small. Especially, the heat transfer from the fin top is negligible when the gap $G_{p}=0 \mathrm{~mm}$. 


\subsection{Simple analyze procedure for pressure drop}

The total pressure drop in the heat sink can be expressed as (Bejan, 1993),

$$
\Delta P_{T}=\Delta P_{c}+\Delta P_{M}+\Delta P_{e}
$$

where, $\Delta P_{c}$ is pressure drop of abrupt contraction at the inlet of heat sink, $\Delta P_{M}$ is that of pin fin rows, and $\Delta P_{e}$ is that of abrupt enlargement at the outlet of heat sink.

Similar to the thermal performance, we apply the tube bank correlation (Holman, 1986) for estimating the pressure drop in pin fins $\Delta P_{M}$. We also assume that the local pressure drop at row $i$ is calculated by using maximum average velocity $U_{\text {maxi }}$ there.

$$
\begin{aligned}
& \Delta P_{M}=\sum \Delta P_{M i} \quad \text { for } 1 \leq i \leq 7 \\
& \Delta P_{M i}=\frac{\rho \cdot U_{\operatorname{maxi}}{ }^{2}}{2} \cdot f_{i} \cdot\left(\frac{\mu_{s}}{\mu_{\infty}}\right)^{0.14} \\
& f_{i}=\left[0.25+\frac{0.118}{\left\{\left(x_{T i}-d_{i}\right) / d_{i}\right\}^{1.08}}\right] \cdot R e_{i}^{-0.16}
\end{aligned}
$$

To calculate $\Delta P_{c}$ and $\Delta P_{e}$, we use the correlation for abrupt contraction and enlargement of compact heat exchangers (Kays and London, 1955; Bejan, 1993),

$$
\begin{array}{ll}
\Delta P_{c}=K_{c} \cdot \frac{1}{2} \cdot \rho U_{\max 1}{ }^{2} & \\
K_{c}=0.4 \cdot\left(1-\sigma^{2}\right)+0.4 & \cdots R e_{i} \leq 2000 \\
K_{c}=0.4 \cdot\left(1-\sigma^{2}\right)+0.1 & \cdots 2000<R e_{i} \leq 10000 \\
\Delta P_{e}=K_{e} \cdot \frac{1}{2} \cdot \rho U_{\max e}{ }^{2} & \\
K_{e}=\left(1-\sigma^{2}\right)-0.4 \cdot \sigma & \cdots R e_{i} \leq 2000 \\
K_{e}=\left(1-\sigma^{2}\right)-0.1 \cdot \sigma & \cdots 2000<R e_{i} \leq 10000
\end{array}
$$

where, $\sigma$ is ratio of cross-sectional to frontal area of heat sink shown as follows.

$$
\sigma=\frac{\left(H_{f}+G\right) \cdot W_{d}-N_{i} \cdot d_{i} \cdot H_{f}}{\left(H_{f}+G\right) \cdot W_{d}}
$$

Further, pumping power $P_{w}$ for driving cooling water in heat sink is calculated by following.

$$
P_{w}=\left(H_{f}+G_{P}\right) \cdot W_{d} \cdot U_{i n} \cdot \Delta P_{T}
$$

\subsection{Verifications of simple analyze procedure}

To verify the validity of the simple analyze procedure described above, we performed several verifications.

\subsubsection{Verifications for uniform pin diameters}

First, we compare with experimental result obtained by water cooled pin fin heat sink (Horiuchi et al., 2015), and some results are shown in Fig.2. This is the case of $50 \mathrm{~mm}$ square heat sink with uniform pin diameter of about $2 \mathrm{~mm}$, pin height of $6 \mathrm{~mm}$, and gap $G_{p}=0 \mathrm{~mm}$. Here, $h_{\text {eff }}$ is an equivalent heat transfer coefficient based on fin base area used by Horiuchi et al. The result of present simple analyze procedure roughly agrees with the experimental result of Horiuchi et al. This result shows the usefulness of present analyze procedure for prediction of overall heat sink performance in a practical accuracy. By the way, this guarantees that simple analyze procedure is valid under the condition of $G_{p}=0 \mathrm{~mm}$. It may be not enough to validate more general conditions $\left(G_{p}>0 \mathrm{~mm}\right)$, although we do this for $G_{p}=1 \mathrm{~mm}$ in the next section. However, the purpose of this procedure is not to provide precise more accurate prediction method for general condition like $G_{p}>0 \mathrm{~mm}$ but to use as a tool for optimization. In this connection, we have used $G_{p}$ as noise factor in Taguchi method. Therefore, validation with Fig. 2 is sufficient for present purpose. Incidentally, Horiuchi and Nishihara (2013) proposed very precise treatment of bypass flow. This can be referred to improve the generality of the simple procedure in future. 


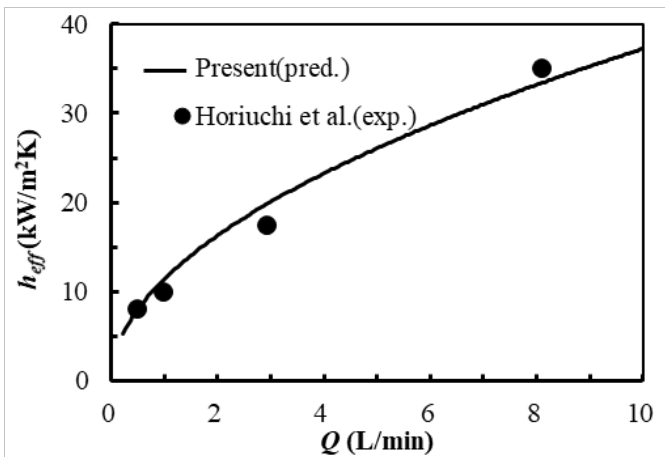

(a) Effective heat transfer coefficient based on heat sink base area

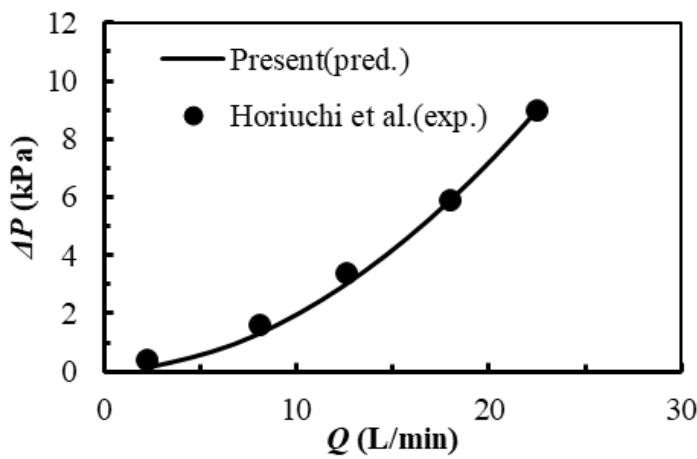

(b) Pressure drop

Fig. 2 Comparison with experimental data of forced water cooling with pin fin heat sink (Horiuchi et al., 2015) .

\subsubsection{Verifications for non-uniform pin diameters}

Example of the heat sink computational model considered in the numerical analysis is shown in Fig. 3. We utilize the advantage of symmetry condition appeared in the basic model of Fig. 1(a), in which the heat sink dimensions are shown. The heat sink base thickness and pins height are specified here to be $2 \mathrm{~mm}$ and $12 \mathrm{~mm}$, respectively. The flow domain is considered as a rectangular box with length of $28 \mathrm{~mm}$, width of $12 \mathrm{~mm}$ and height of $14 \mathrm{~mm}$. The heat source is considered as a thin plate fixed at the center of the heat sink. The free sidewalls of the base and the top boundary of the flow domain are insulated. Heat is transferred by conduction from the hot source through the base into the pin fins and by convection between the base and pin fins to the flowing fluid. Aluminum and Copper were used as materials for the solid domain of the heat sink flow model. The temperature of the heat source is specific at $50^{\circ} \mathrm{C}$. Water $\left(T_{i n}=20^{\circ} \mathrm{C}\right)$ enters the heat sink at $x=0$ with a normal inflow velocity of $0.2 \mathrm{~m} / \mathrm{s}$. The Reynolds number based on eq. (11) is 778 with $d=2 \mathrm{~mm}$. At the outlet ( $x=\mathrm{L}$ ), zero-gage pressure and no heat flux are set as an outflow boundary condition for the water. For the symmetry lines, periodic boundary conditions are applied. Also, no slip boundary condition is applied on the walls of the pins.

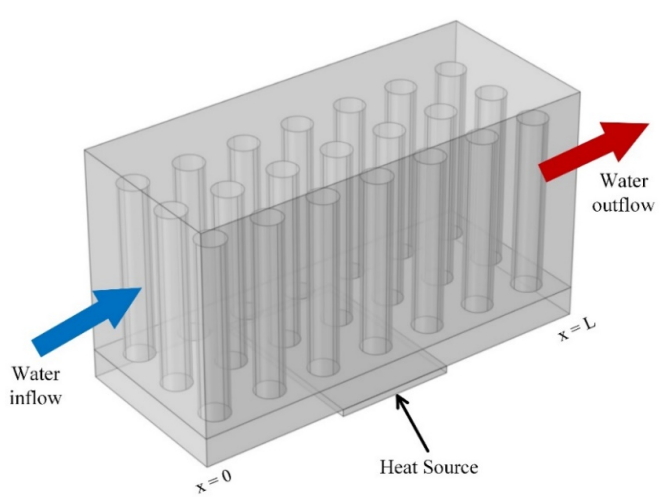

(a) heat sink model

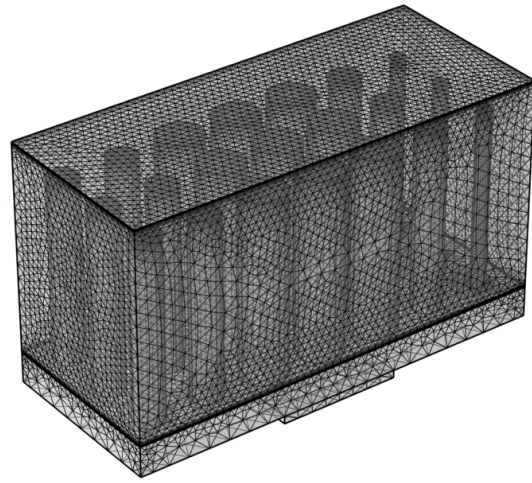

(b) computational mesh

Fig. 3 Computational model of 3D heat sink.

We used a turbulent flow (standard k-epsilon) model. The governing equations were solved numerically using the non-isothermal flow model embedded in $\mathrm{COMSOL}^{\mathrm{TM}}$. This model is used to couple the fluid flow and heat transfer models considering fluid properties such as density and viscosity are temperature dependent. Free tetrahedral elements were used for the mesh of 3D computational domain as shown in Fig. 3. The mesh independent test was carried out. It is confirmed that the average temperature of the fluid at $\mathrm{x}=\mathrm{L}$ is independent over the mesh size of $7.5 \times 10^{5}$ (difference is less than $0.001 \%$ ). Therefore, mesh element used in this study is $7.5 \times 10^{5}$.

Although our proposed simple analyze procedure is basically based on correlations for tube bank, we confirm the applicability of tube bank formulations for rows of different diameters at first. Figure 4 shows the thermal conductance of pin array at $G_{p}=0 \mathrm{~mm}$ when diameter of the 4 th row is morphed $\left(U_{i n}=0.2 \mathrm{~m} / \mathrm{s}\right)$. Figure 4 is the results of thermal conductance at each row by numerical simulation and those by simple analyze procedure when only one row $(i)$ is 
heated. Thus, it means, $C_{i}=A_{p i} \cdot h_{p i}$. The diameter of the 4th row pins was allowed to morph from $2 \mathrm{~mm}$ to $1 \mathrm{~mm}$ and $3 \mathrm{~mm}$, while the remaining pins diameter was fixed $(d=2 \mathrm{~mm})$. The fluid flow is modeled under the assumption of steady and turbulent flow. The velocity and temperature distributions within the computational model were determined by solving the conservation of mass, momentum and energy equations for the flow domain and heat conduction equation in the solid pins. A constant temperature boundary condition $\left(T_{w}=50^{\circ} \mathrm{C}\right)$ is specified at the outer surface of the pins wall for one row in each simulation run starting from the 1 st row throughout the 7 th row. 7 . Constant heat flux condition may be more practical than constant temperature condition in this case. However, both way is possible for obtain and validate the heat transfer coefficient of pin fins. And it seems to be more convenient to compare the results especially for one row heating case like this. And we suppose a conductive metal as a pin material, so temperature distribution in the cross-section of fin may be rather uniform. That is the reason why we cited the constant temperature condition for verification of the present procedure.

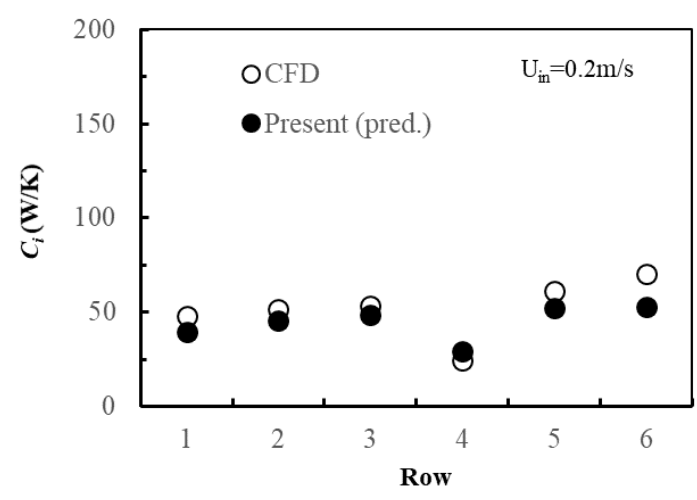

(a) Diameters of 4th row pins are smaller than others

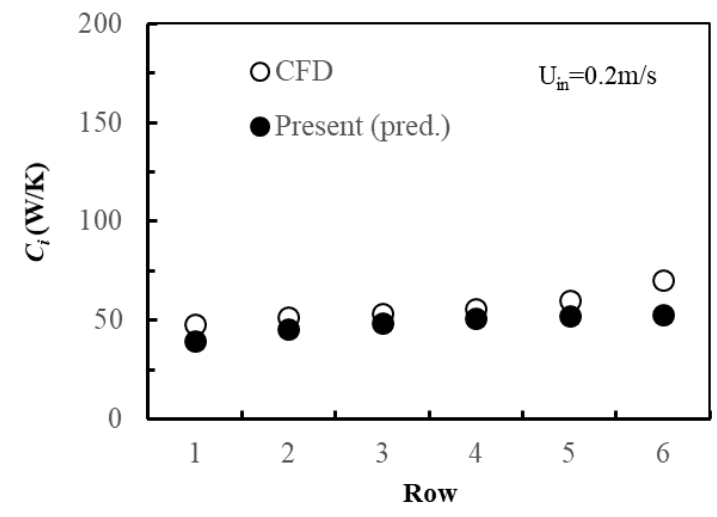

(b) All pins have same diameter

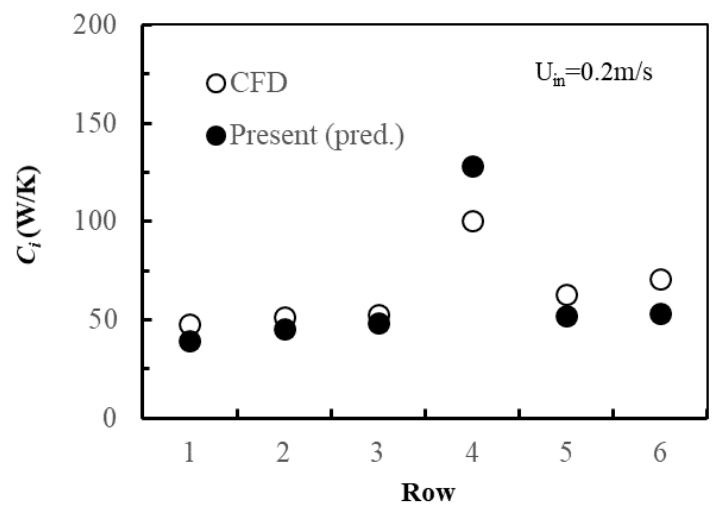

(c) Diameters of 4th row pins are larger than others

Fig. 4 Thermal conductance of pin fins at each row when diameter of 4 th row is morphed. 


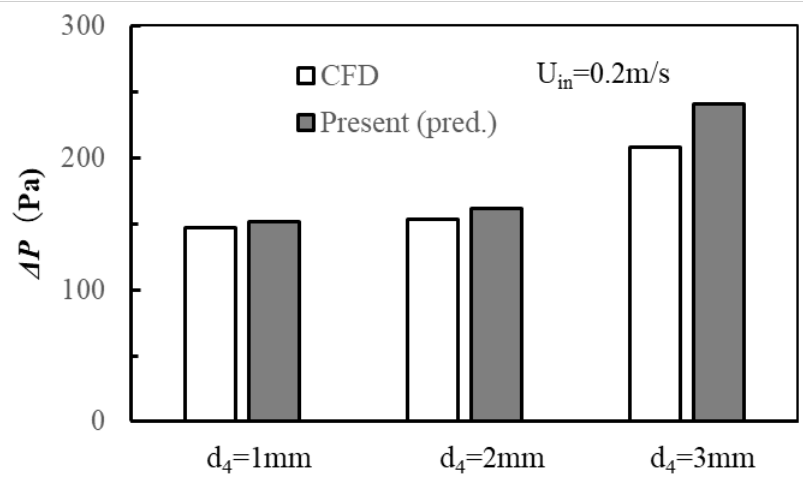

Fig. 5 Pressure drop of pin fin array when diameter of 4th row is morphed.

Figure 5 also compares the results of pressure drop the pin array at $G_{p}=0 \mathrm{~mm}$ along when diameter of 4 th row is morphed.

Figures 4 and 5 indicate the results of thermal conductance and pressure drop by present simple analyze procedure shows almost same tendency with those by CFD numerical simulation.

When we look Fig.4 in detail, there is a relatively large difference in row 4 of Fig. 4(c). We think the difference in row 4 of Fig. 4(c) comes from a little difference in flow structure. As our simplified model is based on correlations for tube bank with uniform diameters, it sometimes overestimates the turbulence a little near the larger diameter pin. This may be the limitation of present procedure. However tendency for different tube diameters accord with CFD results.

Then, we move to verify the heat sink performance by our simple analyze procedure as infinitely long pin arrays. We have compared the three cases as shown in Table 1 with 3D numerical simulation. Case 1 is the copper heat sink with uniform pin diameter of $2 \mathrm{~mm}$. This case is considered as normal. Case 2 is the aluminum heat sink with same shape for Case 1 but material is different. Case 3 is the aluminum heat sink with non-uniform pin diameters along rows. The all models are the same as that shown in Fig. 3. Thus, the heat sink has $28 \mathrm{~mm}$ in length and $12 \mathrm{~mm}$ in fin height, and $2 \mathrm{~mm}$ in heat sink base thickness. Also, there is a gap $G_{p}=1 \mathrm{~mm}$ between fin top and upper wall. Inlet velocity of cooling water is set at $0.2 \mathrm{~m} / \mathrm{s}$, and the temperature of the heat source is fixed at $50^{\circ} \mathrm{C}$.

Figures 6 is temperature distribution within heat sink for Case 1 and Case 3. It is seen from this figure that upper part of pin fins is rather cooled by cooling water even for copper as heat sink material (Case1). Thus, fin efficiency of pin fin may take an important role for water cooling of pin fin heat sinks. In this connection, calculated fin efficiency at 4th row from present procedure is $\eta_{p i}=0.432$ for Case $1, \eta_{p i}=0.338$ for Case 2 and $\eta_{p i}=0.344$ for Case 3 , respectively.

Figure 7 is the comparison of total thermal conductance $C_{T}\left(=1 / R_{T}\right)$ and pressure drop of heat sink between the results by $3 \mathrm{D}$ numerical simulation and present simple analyze procedure. We can see that both results have almost same tendency.

In conclusion, these results for comparison with 3D numerical simulation may suggest the appropriateness of present simple analyze procedure for rows of non-uniform pin diameters.

Table 1 Parameter of pin fin heat sink for 3D CFD simulation.

\begin{tabular}{|c|c|c|c|c|c|c|c|c|}
\hline & material & $d_{1}$ & $d_{2}$ & $d_{3}$ & $d_{4}$ & $d_{5}$ & $d_{6}$ & $d_{7}$ \\
\hline Case 1 & $\mathrm{Cu}$ & $2 \mathrm{~mm}$ & $2 \mathrm{~mm}$ & $2 \mathrm{~mm}$ & $2 \mathrm{~mm}$ & $2 \mathrm{~mm}$ & $2 \mathrm{~mm}$ & $2 \mathrm{~mm}$ \\
\hline Case 2 & $\mathrm{Al}$ & $2 \mathrm{~mm}$ & $2 \mathrm{~mm}$ & $2 \mathrm{~mm}$ & $2 \mathrm{~mm}$ & $2 \mathrm{~mm}$ & $2 \mathrm{~mm}$ & $2 \mathrm{~mm}$ \\
\hline Case 3 & $\mathrm{Al}$ & $2 \mathrm{~mm}$ & $2 \mathrm{~mm}$ & $3 \mathrm{~mm}$ & $3 \mathrm{~mm}$ & $3 \mathrm{~mm}$ & $2 \mathrm{~mm}$ & $1 \mathrm{~mm}$ \\
\hline
\end{tabular}




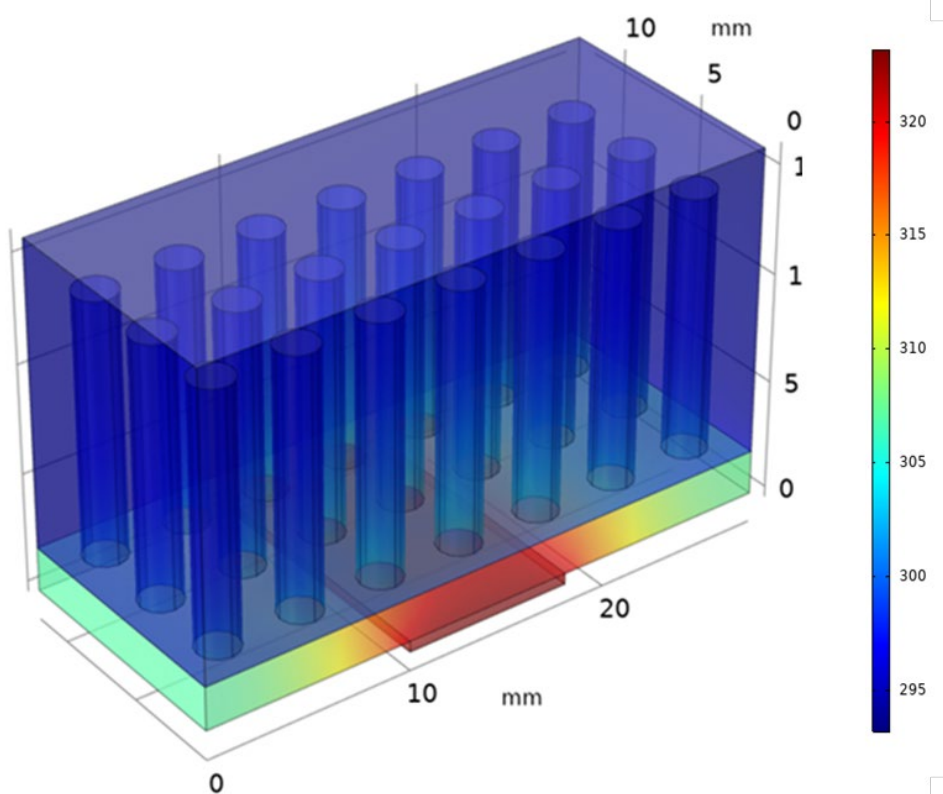

(a) Case 1

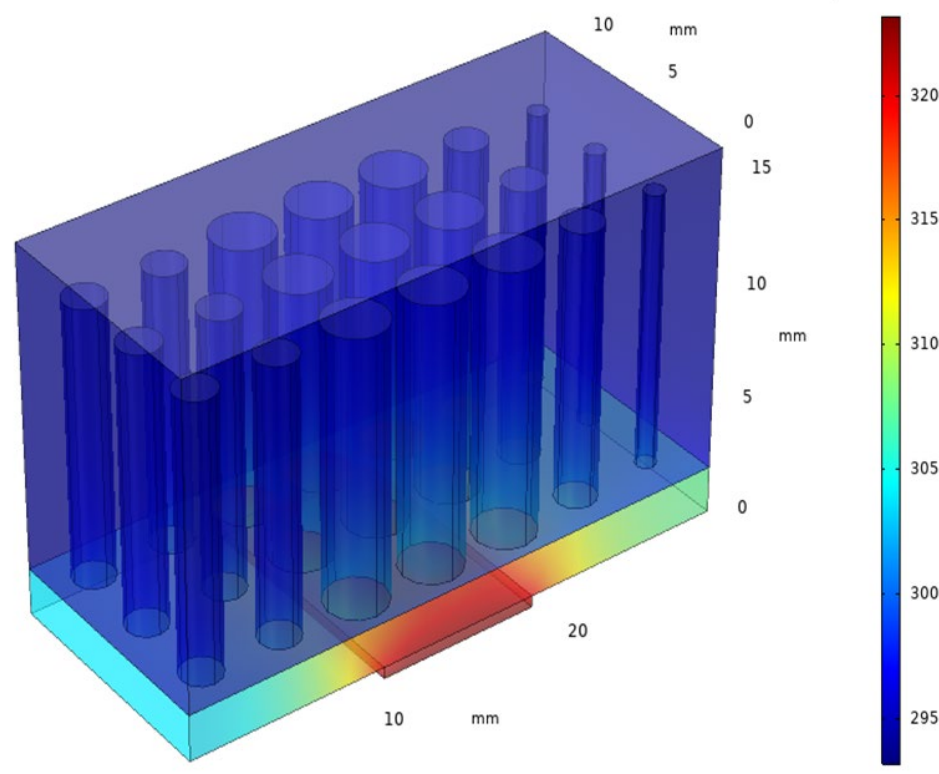

(b) Case 3

Fig. 6 Temperature distribution within the heat sink.

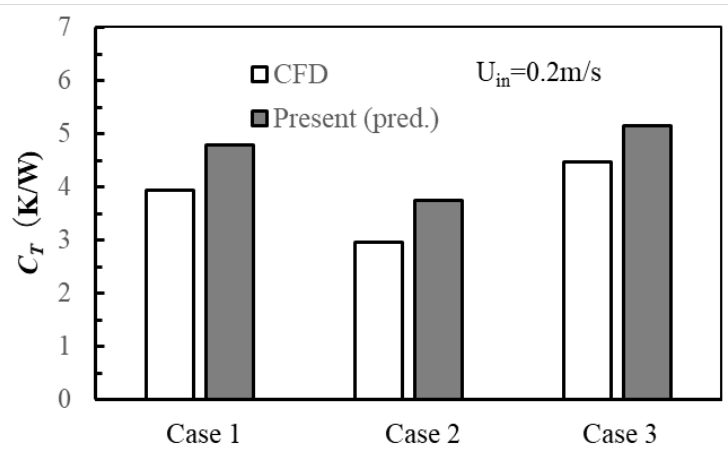

(a) Total thermal resistance

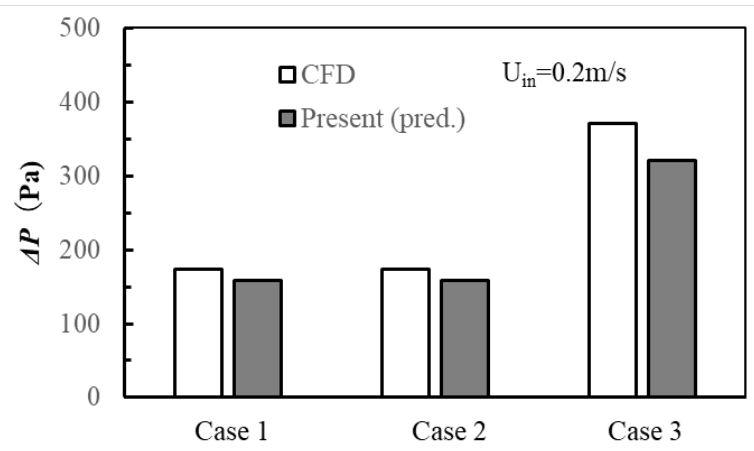

(b) Pressure drop

Fig. 7 Heat transfer performance of heat sink for each Case. 


\section{Optimization procedure of Taguchi method}

In this study, we have used the optimization procedure of the Taguchi method (Nalbant et al. 2007) which enables to evaluate the effective parameters on the performance (objective functions) as well as making the value of objective functions to close around a target value. The parameters used in this study are shown in Table 2. And, we set the objective functions and target value as follows. This means value of the objective functions (1)\&(2) are minimizing after the optimization procedure.

Objective function: (1) $F n=\frac{R_{T}}{R_{T \max }} \quad$ (2) $F n_{1}=\frac{R_{T}}{R_{T \max }}, F n_{2}=\frac{\Delta P}{\Delta P_{\max }}, F n_{3}=\frac{M}{M_{\max }}$

Target value: 0

Where, $\Delta P$ is pressure drop throughout the heat sink and $M$ is heat sink mass including fin base area.

In this study, all parameters in the objective functions are normalized by the maximum value among eighteen cases connection with the L18 orthogonal array shown in Table 3. Then, we sought the optimal combination of the eight heat sink parameters in Table 2. The Reynolds number based on eq. (11) is 272 with $d=1 \mathrm{~mm}, 778$ with $d=2 \mathrm{~mm}$ and 2044 with $d=3 \mathrm{~mm}$, respectively.

Table 2 Eight parameters and levels for optimization.

\begin{tabular}{lcccccccc}
\hline & A & B & C & D & E & F & G & H \\
\cline { 2 - 7 } $\begin{array}{c}\text { Control } \\
\text { factor }\end{array}$ & \multicolumn{7}{c}{ Material } \\
& & \multicolumn{7}{c}{ Diameter of pin fins } \\
\hline Level1 & $\mathrm{Al}$ & $1 \mathrm{~mm}$ & $1 \mathrm{~mm}$ & $1 \mathrm{~mm}$ & $1 \mathrm{~mm}$ & $1 \mathrm{~mm}$ & $1 \mathrm{~mm}$ & $1 \mathrm{~mm}$ \\
Level2 & $\mathrm{Cu}$ & $2 \mathrm{~mm}$ & $2 \mathrm{~mm}$ & $2 \mathrm{~mm}$ & $2 \mathrm{~mm}$ & $2 \mathrm{~mm}$ & $2 \mathrm{~mm}$ & $2 \mathrm{~mm}$ \\
Level3 & - & $3 \mathrm{~mm}$ & $3 \mathrm{~mm}$ & $3 \mathrm{~mm}$ & $3 \mathrm{~mm}$ & $3 \mathrm{~mm}$ & $3 \mathrm{~mm}$ & $3 \mathrm{~mm}$ \\
\hline
\end{tabular}

Table 3 Combination of parameters on L18 orthogonal array.

\begin{tabular}{|c|c|c|c|c|c|c|c|c|}
\hline Case No. & Material & $d_{1}(\mathbf{m m})$ & $d_{2}(\mathbf{m m})$ & $d_{3}(\mathbf{m m})$ & $d_{4}(\mathbf{m m})$ & $d_{5}(\mathbf{m m})$ & $d_{6}(\mathbf{m m})$ & $d_{7}(\mathbf{m m})$ \\
\hline 1 & $\mathrm{Al}$ & 1 & 1 & 1 & 1 & 1 & 1 & 1 \\
\hline 2 & $\mathrm{Al}$ & 1 & 2 & 2 & 2 & 2 & 2 & 2 \\
\hline 3 & $\mathrm{Al}$ & 1 & 3 & 3 & 3 & 3 & 3 & 3 \\
\hline 4 & $\mathrm{Al}$ & 2 & 1 & 1 & 2 & 2 & 3 & 3 \\
\hline 5 & $\mathrm{Al}$ & 2 & 2 & 2 & 3 & 3 & 1 & 1 \\
\hline 6 & $\mathrm{Al}$ & 2 & 3 & 3 & 1 & 1 & 2 & 2 \\
\hline 7 & $\mathrm{Al}$ & 3 & 1 & 2 & 1 & 3 & 2 & 3 \\
\hline 8 & $\mathrm{Al}$ & 3 & 2 & 3 & 2 & 1 & 3 & 1 \\
\hline 9 & $\mathrm{Al}$ & 3 & 3 & 1 & 3 & 2 & 1 & 2 \\
\hline 10 & $\mathrm{Cu}$ & 1 & 1 & 3 & 3 & 2 & 2 & 1 \\
\hline 11 & $\mathrm{Cu}$ & 1 & 2 & 1 & 1 & 3 & 3 & 2 \\
\hline 12 & $\mathrm{Cu}$ & 1 & 3 & 2 & 2 & 1 & 1 & 3 \\
\hline 13 & $\mathrm{Cu}$ & 2 & 1 & 2 & 3 & 1 & 3 & 2 \\
\hline 14 & $\mathrm{Cu}$ & 2 & 2 & 3 & 1 & 2 & 1 & 3 \\
\hline 15 & $\mathrm{Cu}$ & 2 & 3 & 1 & 2 & 3 & 2 & 1 \\
\hline 16 & $\mathrm{Cu}$ & 3 & 1 & 3 & 2 & 3 & 1 & 2 \\
\hline 17 & $\mathrm{Cu}$ & 3 & 2 & 1 & 3 & 1 & 2 & 3 \\
\hline 18 & $\mathrm{Cu}$ & 3 & 3 & 2 & 1 & 2 & 3 & 1 \\
\hline
\end{tabular}

To evaluate the optimal combination of parameters which archive the minimum value of objective functions, $S / N$ ratio $\eta$ and Sensitivity $S$ defined as below (Hirose and Ueda, 2008) are calculated using the present simple analyze procedure shown in chapter 2 . The combination of parameters with lowest Sensitivity $S$ would give us a minimum value of objective functions, while higher value of $S / N$ ratio $\eta$ guarantee the correctness of the analysis for Sensitivity; $S$.

$$
\begin{array}{ll}
\text { S/N ratio } \eta: & \eta=10 \log \left\{\frac{\frac{1}{n} \cdot\left(S_{m}-V_{e}\right)}{V_{e}}\right\} \\
\text { Sensitivity } \mathrm{S}: & S=10 \log \left\{\frac{1}{n} \cdot\left(S_{m}-V_{e}\right)\right\}
\end{array}
$$


Where, $S_{m}$ : fluctuation of mean value of objective function, $V_{e}$ :error of dispersion of objective function, $n$ : number of objective functions.

$$
\begin{aligned}
& S_{m}=(F n 1+F n 2+\quad+F n n)^{2} / n \\
& V_{e}=\left\{\left(F n 1^{2}+F n 2^{2}+F n n^{2}\right)-S_{m}\right\} /(n-1)
\end{aligned}
$$

\section{Results and Discussions}

\subsection{Optimum structure for minimum thermal resistance}

Figure 8 represents the sensitivity $S$ for the cases of $U_{i n}=0.2 \mathrm{~m} / \mathrm{s}$ and $P_{w}=0.1 \mathrm{~W}$ using the objective function (1) for minimum thermal resistance. The combination of parameters with lowest sensitivity would give us an optimum structure for this case. And, we find that the heat sink of maximum pin diameters with copper as material is an optimal structure both for constant inlet velocity $U_{i n}$ and constant pumping power $P_{w}$ cases. The configuration of optimum heat sink for these cases is shown in Fig. 9.

The result for constant inlet velocity $U_{\text {in }}$ case is understandable. Because we do not necessary to consider the increment of pressure drop in the heat sink for this case. So, most dense pin fin array with largest pin diameter should show the highest performance. However, it is rather surprising that the optimum structure for constant pumping power $P_{w}$ case also shows the same result as that for constant inlet velocity $U_{\text {in }}$ case. Because usually increment of pressure drop causes the increase in pumping power. However, result of Figs. 8 and 9 shows, even for constant pumping power case, most dense pin fin array give the highest performance when reduction of thermal resistance of heat sink is a primal issue.

\subsection{Optimum structure for minimum thermal resistance, pressure drop and mass}

We find that most dense pin fin array with largest pin diameter has highest performance even for constant pumping power case. However, it may be better to operate pumps under lower pressure drop conditions from practical point of view. Because internal energy loss in a pump at high-pressure drop condition cannot be disregarded in operation of actual flow systems. Furthermore, in some systems like mobile vehicles, weight of the system may be an important issue. From these reasons, we try to seek the optimum structure for minimum thermal resistance, pressure drop or mass.

Figure 10(a) is the optimum structure for simultaneous minimization of thermal resistance $R_{T}$, pressure drop $\Delta P$ and heat sink mass $M$ at $P_{w}=0.1 \mathrm{~W}$. We use the objective functions (2) for this case. Optimum heat sink is rows of middle pin diameters with aluminum as material for this case. This may be a well-balanced shape for simultaneous reduction of thermal resistance, pressure drop and heat sink mass. Incidentally, this structure is almost the same as that of 3D CFD simulation model for Case 2 in Table 1.

Situation is changed largely when two of objective functions among the three functions in (2) are cited. Figure 10 (b) is the optimum structure for minimum values of thermal resistance $R_{T}$ and pressure drop $\Delta P$ at $P_{w}=0.1 \mathrm{~W}$. Optimum structure of pin fin heat sink for this case is a "wing like shape" with larger pin diameters near the center rows and copper as material. The result of optimal structure of "wing-like structure" from the flow and temperature point of view seems to be indicating the importance of keeping balance between pressure drop and thermal resistance on unit pressure drop basis. Thus, it is effective to decrease the pressure drop at inlet and outlet of pin fin heat sink by reducing the pin diameters and to reduce the surface thermal resistance in center area by increasing the pin diameters for improvement of the thermal performance. We have evaluate the validity of our simple analyze procedure to "wing-like structure" using the 3D simulation (Case 3 of Fig. 7). As shown, results of our simple analyze procedure and CFD are similar.

Figure $10(\mathrm{c})$ is the optimum structure for minimum values of thermal resistance $R_{T}$ and heat sink mass $M$ at $P_{w}=0.1 \mathrm{~W}$. Optimum structure of pin fin heat sink for this case is rows of maximum pin diameters with aluminum as material.

Figure $10(\mathrm{~d})$ is the optimum structure for minimum values of pressure drop $\Delta P$ and heat sink mass $M$ at $P_{w}=0.1 \mathrm{~W}$. Optimum structure of pin fin heat sink for this case is rows of minimum pin diameters with aluminum as material. 


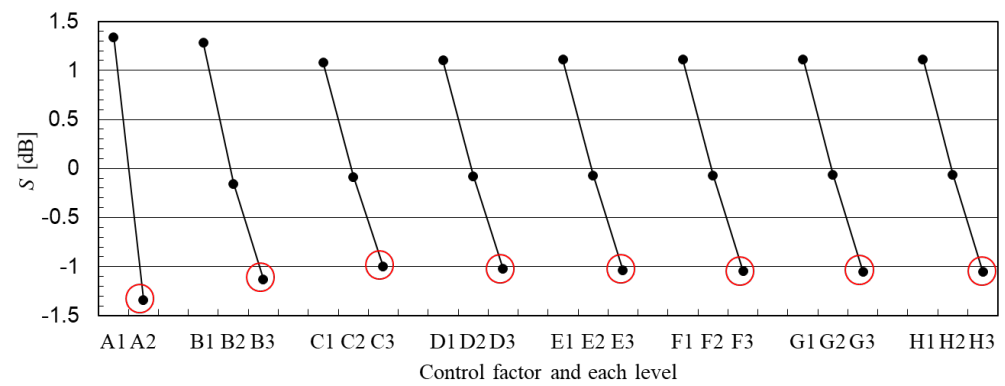

(a) $U_{\text {in }}=0.2 \mathrm{~m} / \mathrm{s}$ (zero point is average $-21.1 \mathrm{~dB}$ )

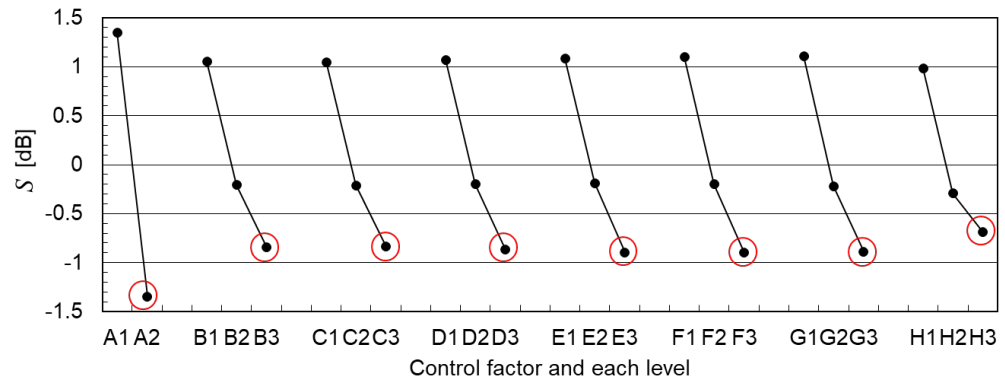

(b) $P_{w}=0.1 \mathrm{~W}$ (zero point is average $-23.1 \mathrm{~dB}$ )

Fig. 8 Result of sensitivity on parametric study for minimum $R_{T}$.

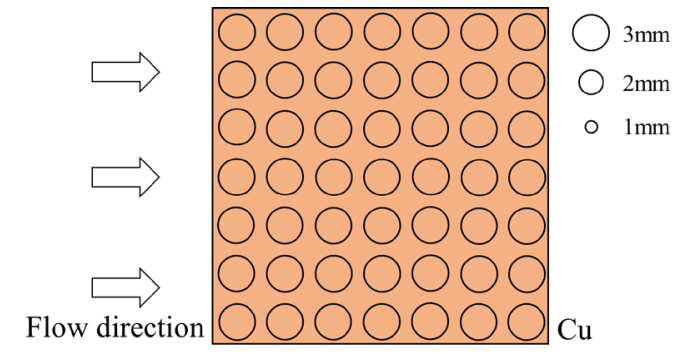

Fig. 9 Optimum structure for minimum $R_{T}\left(U_{i n}=0.2 \mathrm{~m} / \mathrm{s} \& P_{w}=0.1 \mathrm{~W}\right)$.

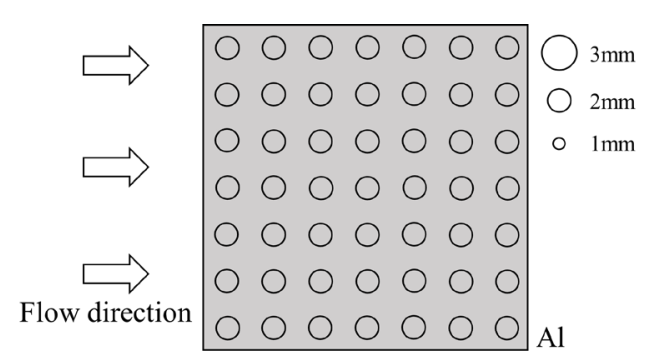

(a) $R_{T} \& \Delta P \& M$.

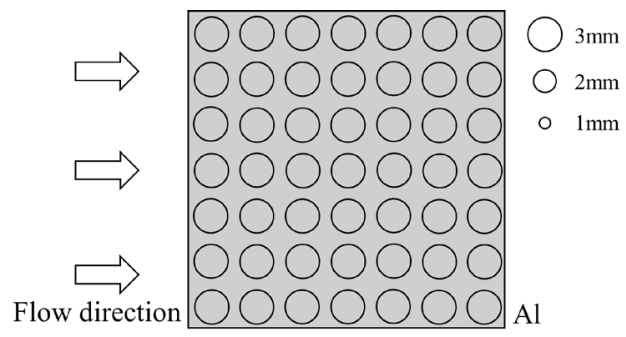

(c) $R_{T} \& M$.

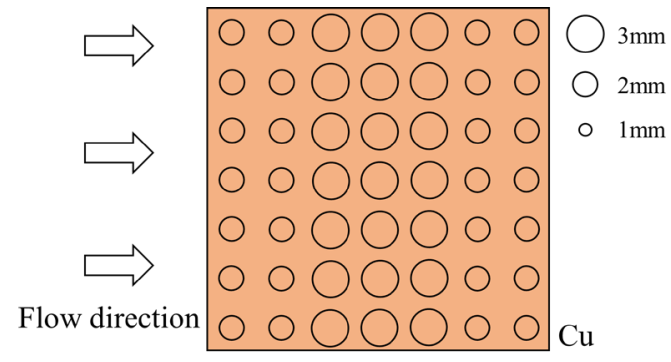

(b) $R_{T} \& \Delta P$.

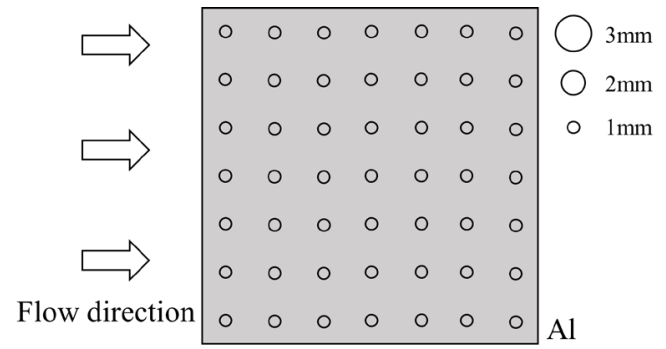

(d) $\triangle P \& M$.

Fig. 10 Optimum structure for minimum objective functions $\left(P_{w}=0.1 \mathrm{~W}\right)$. 


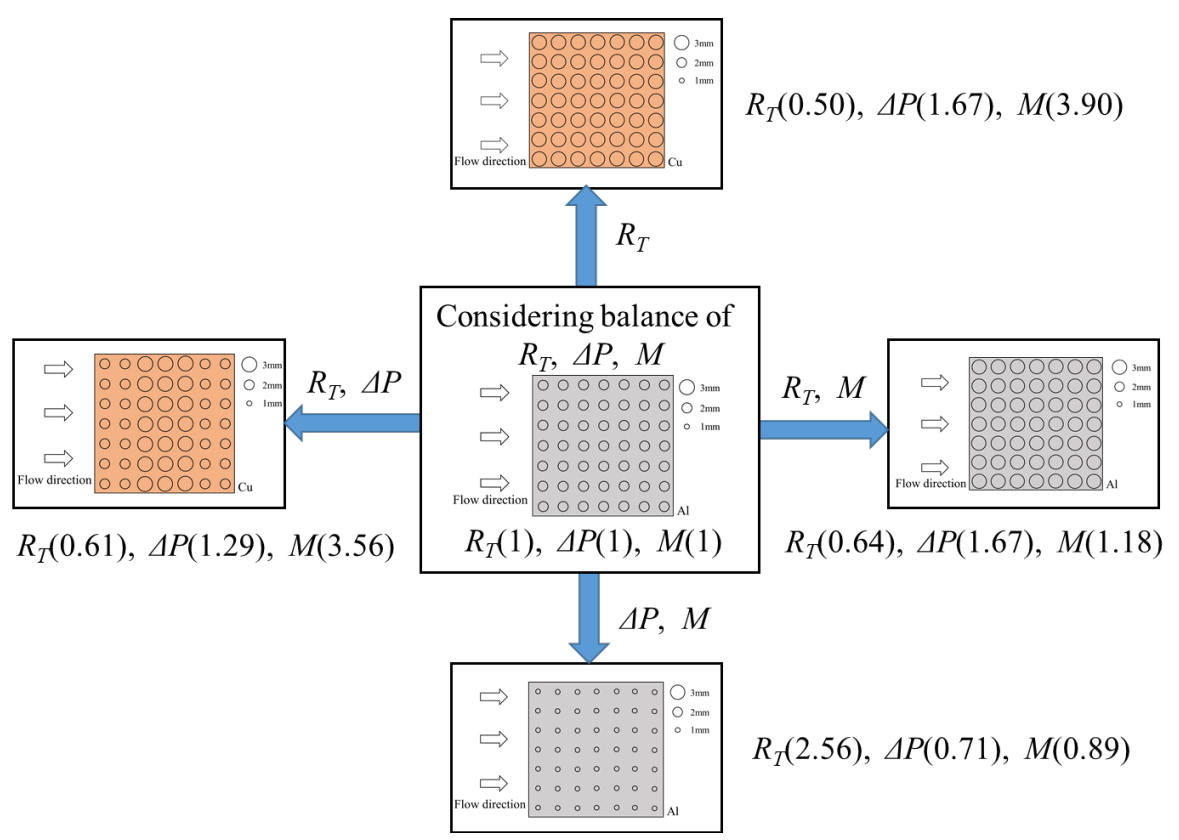

Fig. 11 Change of optimum structure and performance with requirement of objective functions among $R_{T}, \Delta P \& M$

$$
\left(P_{w}=0.1 \mathrm{~W}\right) \text {. }
$$

Figure 11 is the summary of optimum structure and its cooling performance depending on the requirement of performance among thermal resistance, pressure drop and mass at $P_{w}=0.1 \mathrm{~W}$. In this figure, the performance of heat sink at the optimum structure for simultaneous minimization of thermal resistance $R_{T}$, pressure drop $\Delta P$ and heat sink mass $M$ is cited as normal. When the thermal resistance is the only priority, thermal resistance $R_{T}$ could reduce by half. However, pressure drop $\Delta P$ increases 1.67 times and also heat sink mass $M$ increases 3.90 times as a penalty. Then, when the thermal resistance and the pressure drop are the first priority, thermal resistance $R_{T}$ could reduce by 0.61 times with the slight increase in pressure drop $\Delta P$ by 1.29 times. However heat sink mass $M$ increases 3.56 times as a penalty. Next, when the thermal resistance and the mass of heat sink are the first priority, thermal resistance $R_{T}$ could reduce by 0.64 times with the slight increase in heat sink mass $M$ by 1.18 times. But pressure drop $\Delta P$ increases 1.67 times as a penalty. Finally, when the pressure drop and the heat sink mass are the first priority, pressure drop $\Delta P$ reduces 0.71 times and heat $\operatorname{sink}$ mass $M$ also reduces 0.89 times with increase in thermal resistance $R_{T}$ by 2.56 times as a penalty.

\section{Conclusion}

In this paper, we studied the relationship between the heat sink design and thermal resistance, pressure drop and structure mass. The heat sink was endowed a freedom to morph its pins size toward improving the thermal performance. For this purpose, we have developed a simple analysis for pin fin heat sink which allows to evaluate the row-by-row heat transfer amount along the water flow direction. The validation of the simple analysis were conducted for uniform and non-uniform pin diameter and the results were compared with an experimental result from the literature and numerical result by CFD. Then, the optimal design of pin fin heat sink was selected based on the best performance using the Taguchi method.

The results show that the optimum structure of heat sink related to a minimum thermal resistance is the one where the pin diameter is uniformly $3 \mathrm{~mm}$ built from copper. This outcome was correct for constant inlet velocity $U_{i n}$ case and constant pumping power $P_{w}$ case. Also, optimum structure of heat sink for low thermal resistance, low pressure drop and light weight heat sink is when the heat sink is constructed from aluminum with $2 \mathrm{~mm}$ pin. However, the structure varies based on the priority among the three objective functions. When the thermal resistance and the pressure drop are considered, the best structure is the "wing like shape" with larger pin diameter at center rows and copper as material. When the thermal resistance and the heat sink mass are of interests, top structure is associated with uniform pin diameter of $3 \mathrm{~mm}$ built from aluminum. Lastly, if the pressure drop and heat sink weight are the priorities, the structure with aluminum pin diameter of $1 \mathrm{~mm}$ seems to be the best performed design. 


\section{Acknowledgement}

One of authors (HM) would express appreciation to his former student Shunichiro OHIWA who did the preliminary work of this study.

\section{References}

Ashiwake, N., Nakayama, W., Daikoku, T. and Kobayashi, F., Forced convective heat transfer from LSI packages in an air-cooled wiring card array, Heat Transfer in Electronic Equipment-1983 HTD-Vol.28(1983),pp.35-42, ASME.

Bejan, A., Heat Transfer (1993), pp. 60, 244, 270-273, 480-485, Wiley.

Bejan, A., The Physics of Life: The evolution of everything (2016), St. Martin's Press, New York.

Bello-Ochende, T., Meyer, J. P. and Bejan. A., Constructal multi-scale pin-fins, International Journal of Heat and Mass Transfer, No. 53 (2010), pp. 2773-2779.

Hirose, H. and Ueda, T., An Introduction to Taguchi Method Analysis by Excel(2008), pp. 3-13, pp. 95-133, Doyukan(in Japanese).

Holman, J.P., Heat Transfer (1986), p. 301, McGraw-Hill.

Horiuchi, K., Nishihara, Experimental verification of model for liquid-cooled staggered pin fin heat sinks with top bypass flow, Journal of Energy and Power Engineering, 7 (2013), pp.1487-1495.

Horiuchi, K., Nishihara, A., Sugimura, K., Multi-objective optimization of water-cooled pinfin heatsinks, International Journal of Heat and Mass Transfer, No. 81 (2015), pp. 760-766.

Kays, W.M. and London, A.L., Compact Heat Exchangers (1955), p.64, McGraw-Hill,NY.

Matsushima, H, Almerbati, A. and Bejan, A., Evolutionary design of conducting layers with fins and freedom, International Journal of Heat and Mass Transfer, No.126 (2018), pp. 926-934.

Matsushima, H, Almerbati, A. and Bejan, A., Evolutionary design with freedom: Time dependent heat spreading, International Communications in Heat and Mass Transfer, No.108 (2019), 104335.

Nalbant, M., Gokkaya, H., Sur, G., Application of Taguchi method in the optimization ofcutting parameters for surface roughness in turning, Materials and Design, Vol.28 (2007) pp. 1379-1385.

The Japan Society of Mechanical Engineers ed., Electronic Cooling Handbook (1996), p.1.1-2(in Japanese).

The Japan Society of Mechanical Engineers ed., Heat Transfer (2005), Maruzen, p.71, p. 195(in Japanese).

Ramphueiphad, S. and Bureerat, S., Synthesis of multiple cross-section pin fin heat sinks using multiobjective evolutionary algorithms, International Journal of Heat and Mass Transfer, No. 118 (2018), pp. 462-470.

Žukauskas, A., Heat Transfer from Tubes in Crossflow, Advances in Heat Transfer, 8 (1972), pp. 93-160. 